\title{
Torsten Jantsch
}

\section{Jesus, der Retter}

\section{Die Soteriologie des lukanischen Doppelwerks}

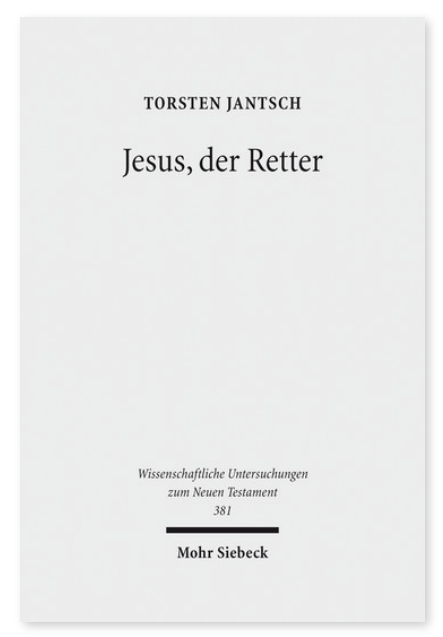

2017. XV, 398 Seiten. WUNT I 381

ISBN 978-3-16-155594-7

DOI 10.1628/978-3-16-155594-7

eBook PDF 159,00€

ISBN 978-3-16-155189-5

Leinen $159,00 €$
Torsten Jantsch geht in dieser Studie in semantischen und narratologischen Analysen den nach wie vor umstrittenen Fragen nach, was nach Lukas Inhalt des Heils ist und wie dieses im lukanischen Doppelwerk begründet wird. Der Autor legt eine Rekonstruktion der lukanischen Soteriologie vor, bei der die verschiedenen und in der Forschung oft unverbunden nebeneinander stehenden soteriologischen Vorstellungen im lukanischen Doppelwerk in ein Gesamtkonzept integriert sind. Er zeigt zudem, dass Lukas das irdische Wirken Jesu und seine Position als zu Gott Erhöhtem in einen kohärenten Zusammenhang bringt und von daher seine Soteriologie entwickelt, indem er die Geschichte des Retters Jesus erzählt. Lukas entwirft damit das Bild eines konsequent in der Person Jesu begründeten Heils. Er stellt zwar nicht den Tod Jesu in das Zentrum seiner Soteriologie - aber die Person des erhöhten Retters.

Torsten Jantsch Geboren 1976; 1996-2002 Studium der Ev. Theologie; 2004-09 Pfarrdienst; 2009 Promotion; 2009-11 wissenschaftlicher Mitarbeiter, 2011-17 Akademischer Rat im Beamtenverhältnis auf Zeit an der Evangelisch-Theologische Fakultät der LMU München; 2015 Habilitation; derzeit Privatdozent an der Evangelisch-Theologische Fakultät der LMU München.

https://orcid.org/0000-0002-7834-3105

Jetzt bestellen:

https://mohrsiebeck.com/buch/jesus-der-retter-9783161555947?no_cache=1

order@mohrsiebeck.com

Telefon: +49 (0)7071-923-17

Telefax: +49 (0)7071-51104 